\title{
Wittgenstein's comparison between philosophy, aesthetics and ethics
}

\author{
Oskari Kuusela
}

Wittgenstein compares philosophical explanations with explanations in aesthetics and ethics. According to him, the similarity between aesthetics and philosophy 'reaches very far', and as I aim to show, the comparison can be used to elucidate certain characteristic features of Wittgenstein's philosophical approach. In particular, it can explain how his approach differs from metaphysical philosophy as well as clarifying the sense in which there are no theses or theories in philosophy, as Wittgenstein conceives it. In the last section of the essay, I examine certain consequences of Wittgenstein's view, including the lack of conclusive arguments in philosophy. Rather than implying that philosophy falls short of its rational aspirations, I argue, Wittgenstein's explanation of why there are no conclusive arguments in philosophy can help us to see in the right light the lack of agreement in philosophy, as well as explaining why this is not a defect.

\section{Comparisons between philosophical, aesthetic and ethical explanations}

In his writings, especially in the 1930s but later too, Wittgenstein occasionally compares philosophy and philosophical explanations with aesthetic explanations. This is exemplified by the first quote in the following that describes the similarity between the two as reaching 'very far'. As I will argue, Wittgenstein's comparison is quite instructive about his philosophical approach in that it can be used to explain how his philosophical approach 
differs from metaphysical philosophy, as well as clarifying the sense in which there are no theses in philosophy as he conceives of it. ${ }^{1}$ Wittgenstein writes:

The strange resemblance between a philosophical investigation (perhaps especially in mathematics) and one in aesthetics, e.g. what is bad about this garment, how it should be, etc.

There too the question is ${ }^{2}$ : "What does not yet fit here" \& there too a blunter feeling says: "everything is already in order". There too one should not throw away the false explanation because it is useful for finding the right one // for it is a part of the way that leads to the correct one. The similarity reaches very far. (MS 119: 89-89r; first paragraph also in MS 116: 56/CV: 29)

I will return to the point about false explanations in the last section of the essay, having first discussed how the comparison helps to clarify certain characteristic features of Wittgenstein's philosophical approach. First, however, let me quote two more remarks on the philosophyaesthetics comparison - or as we might also say philosophy-aesthetics-ethics comparison. For sometimes this third member, too, is brought into the comparison, and Wittgenstein clearly regards these three areas of discourse as linked by certain structural features manifested in what explanation and justification is in each area. G. E. Moore reports from Wittgenstein's lectures:

Reasons, he said, in Aesthetics, are "of the nature of further descriptions": e.g. you can make a person see what Brahms was driving at by showing him lots of different pieces by Brahms or by comparing him with a contemporary author; and all that Aesthetics does is "to draw your attention to a thing", to "place things side by side". [...] And he said that the same sort of "reasons" were given, not only in Ethics, but also in Philosophy. (Moore 1955: 19, cf. 27; my square brackets; I will discuss the part edited out in section 3.)

\footnotetext{
${ }^{1}$ By metaphysical philosophy I will understand here philosophy that puts forward theses about necessities claimed to underlie the empirical contingencies encountered in experience. I return to this in section 2.

2 "Es heist eben auch da..."
} 
Finally, consider the following remark on philosophical and ethical problems from a notebook in the 1930s: 'As in philosophy so in life we are led astray by seeming analogies (to what others do or a permitted to do). And here, too, there is only one remedy against this seduction: to listen to the soft voices which tell us that things here are not the same as there.' (MS 183: 88/PPO: 97)

A common point in the last two quotes is that thinking in philosophy, aesthetics and ethics involves making comparisons as a way of rendering things comprehensible. Regarding explanations in aesthetics specifically, I take Wittgenstein's point to be explainable roughly as follows. Different pieces from Brahms brought together can be employed to bring to view something characteristic of his music, i.e. 'what he was driving at'. (This need not necessarily be something common to all works of Brahms, but could be a network of similarities.) Additionally, however, comparisons with other composers are important too, because differences are equally significant as similarities for understanding what is characteristic of something. Correspondingly, comparisons are important in ethics in order for one not to be misled by tendencies of thought that pull one in the wrong direction, as Wittgenstein explains. We must be wary of false analogies which suggest that certain cases are similar when they are not, and thus we ought to listen to the 'soft voices' that tell us things are not the same here as there. Perhaps this may be rephrased in terms of the first quote. In ethics just as in aesthetics and philosophy, there is a risk of being misled by 'a blunter feeling' that drowns the 'soft voices', and suggests that things are already in order and worked out. However, in order to further unpack these remarks, let us turn to their connections with other remarks Wittgenstein makes about his philosophical approach. For, relevant points are developed more fully in many of his methodological or metaphilosophical remarks that do not mention aesthetics or ethics. We can use such remarks as an aid for clarifying Wittgenstein's comparisons between philosophy, aesthetics and ethics. 


\section{Connections with Wittgenstein's other remarks on his philosophical approach}

To explain how Wittgenstein's remarks on his philosophical approach can help to understand the aesthetics-ethics comparisons, consider the following remark on the contrast between metaphysical philosophy and Wittgenstein's own approach. The latter he describes as a conceptual investigation concerned with conceptual questions rather than factual questions, a distinction which, according to him, remains unclear in metaphysical philosophy. Like any factual investigation, a metaphysical one puts forward true/false assertions or theses about its objects of investigation, although it does not conceive itself as concerned with merely contingent facts. Wittgenstein writes:

Philosophical investigations: conceptual investigations. The essential thing about metaphysics: that the difference between factual and conceptual investigations is not clear to it. A metaphysical question is always in appearance a factual one, although the problem is a conceptual one. (MS 134: 153/RPP I: §949; cf. BB: 18, 35)

One could be excused for wondering whether this has anything to do with the remarks on aesthetics and ethics, and whether Wittgenstein's critique of metaphysics has any connection with the aesthetics and ethics comparison. Indeed, insofar as we regard his critique of metaphysics as central to his later philosophy - as I would certainly do -, such a lack of connection might naturally be taken to indicate the superficiality of the comparison with aesthetics and ethics. However, that an intimate connection exists becomes evident in Wittgenstein's next remark that clarifies the contrast between factual and conceptual investigation, and explains what a conceptual investigation is or what it does: 
What is it, however, that a conceptual investigation does? Does it belong in the natural history of human concepts?-Well, natural history, we say, describes plants and beasts. But might it not be that plants had been described in full detail, and then for the first time someone realized the analogies in their structure, analogies which had never been seen before? And so, that he establishes a new order among these descriptions. He says, e.g., "compare this part, not with this one, but rather with that" (Goethe wanted to do something of the sort) and in so doing he is not necessarily speaking of derivation; nonetheless the new arrangement might also give a new direction to scientific investigation. He is saying "Look at it like this"--and that may have advantages and consequences of various kinds. (MS 134: 154/RPP I: $\$ 950)^{3}$

As Wittgenstein explains, a conceptual investigation is not an empirical or factual investigation of our concepts or of the linguistic practices in which they find their expression. A conceptual investigation does not seek to establish facts about language use, analogously with a natural historical investigation of plants or beasts, and in this sense it does not constitute a special branch of natural history: the natural history of the language use of humans. ${ }^{4}$ Rather, as illustrated by Wittgenstein's example of someone who develops a new way of looking at plants and their relations, and invites another to look at plants in this new way, a conceptual investigation is concerned with developing modes of representing things or modes conceiving of looking at them. (I will come back to these notions shortly.) Moreover, as Wittgenstein explains, the new way of looking, arrived at by comparing different plants and their parts, establishes or creates a new order among the objects of study. This is illustrated by someone producing a new order amongst our descriptions of plants, i.e. organizing in a novel way the factual knowledge that a natural history has already collected. Hence, although a conceptual investigation does not aim to establish facts, it has its own kind of significance. As Wittgenstein notes, a new conceptual order or a new way of looking at

\footnotetext{
${ }^{3}$ In what follows I will refer to this remark as 'the conceptual investigation remark'.

${ }^{4}$ For an interpretation of PI 2009: 415, where Wittgenstein speaks of himself as making remarks on the natural history of humans, which is consistent with the reading proposed here, see Kuusela forthcoming: Chapter 6.3.
} 
plants "may have advantages and consequences of many kinds", inclusive of it giving a new direction to factual, scientific investigation.

The notion of ordering or organizing calls for particular attention in this connection. When Wittgenstein speaks in the quote about ordering things, and of articulating a way of looking at things in this way, he is referring to something the significance of which we are, I think, very well aware, although may often fail to pay attention to it. As every museum curator presumably recognizes, and museum goers understand at least implicitly, the way in which things are placed together in an exhibition - whether an art show or in a natural history museum - can significantly influence how we perceive and understand the nature of the exhibited objects. For example, a retrospectively organized exhibition of the paintings of a painter can bring to view lines in the development of her work that would otherwise be obscured and very difficult or impossible to detect. As a consequence the paintings may appear in a quite different light. Likewise the arrangement of organisms in a natural history museum can significantly influence one's understanding of the exhibited organisms due to how it places them in, for example, evolutionary history, in relation to what went on before and what came after. As these examples illustrate, our perception of things can be significantly influenced by the way they are arranged and organized. The point is that to simply place objects side side, to arrange them in a particular way already constitutes a mode of representing them which can significantly influence our understanding of them. Such an arrangement does not only constitute a way of directing attention, but by directing attention it invites and is conducive to particular ways of seeing and conceiving the objects in question.

As noted, according to Wittgenstein, a way of ordering things can give a new direction to science. But it can also play an important role in philosophy. A good example is Wittgenstein's suggestion to conceive first person expressions of pain, not as knowledge claims regarding inner states, but as manifestations of pain that are similar to pre-linguistic 
primitive pain behaviour, such as crying and moaning (PI 2009: 244). As a consequence of this novel comparison between first person pain expressions and relevant primitive modes of behaviour, certain problems can be solved which arise with the traditional view of sensationexpressions as knowledge claims concerning inner states. In essence, what Wittgenstein achieves with this new comparison is a re-conceptualization of the logical function of first person expressions of sensations, whereby certain first person pain expression are reclassified as not belonging to the class of true/false propositions or descriptions. This in turn is philosophically highly significant in that, consequent to this re-conceptualization, person A's claim to know person B's pain no longer needs to be thought of as a problematic knowledge claim about an inner object impossible for A to access. Rather, we now have an alternative to the traditional philosophical account of sensation-talk that excludes us from knowing anyone else's sensations, holding us in the grip of the so-called problem of other minds. Alternatively, if instead we regard A's knowledge of B's pain as based on A's perception of B's pain through its immediate expressions, a solution to the problem can arguably be found. What figures in the traditional account as an inner object inaccessible to others can now be reclaimed and made accessible to others with the help of the notion of expressive behaviour. In this way, Wittgenstein's reclassification of the function of first person pain expressions aims to solve the problem of other minds by changing the way we conceive the function of relevant expressions.

The preceding does not yet explain how Wittgenstein's aesthetics-ethics comparison can help to understand the difference between his philosophical approach and metaphysical philosophy. Hopefully, however, my pocket-size outline of parts of Wittgenstein's private language discussion, in light of what he says about conceptual investigation, gives some idea of the potential and philosophical strength of Wittgenstein's approach. And in fact, we are already almost in a position to see how Wittgenstein's approach differs from metaphysical 
philosophy. We only need to see some further connections which I am now in a position to indicate.

That re-conceptualizing what is philosophically problematic is central to how Wittgenstein conceives of the task of philosophy - and not an idea buried in the manuscript from which I quoted - is easy to show. There are numerous remarks to this effect in his Nachlass. I will simply quote one from the early 1930s that puts the point in quite a different way, with some Tractarian echoes: 'As I do philosophy, its entire task consists in expressing myself in such a way that certain problems disappear.' (TS 213: 421/PO: 189; cf. MS 140: 10; MS 183: 65; PI 2009: 90, 93) Arguably, despite its rather different appearance, this remark expresses the same methodological idea that I used the pain-example to illustrate: a philosophical problem can be dissolved through the transformation of one's way of speaking and thinking about the matter at hand, that is, through re-conceptualization or by changing one's way of looking at it. This, however, is just what the remark about conceptual investigation speaks about too, except that the example Wittgenstein gives relates to changing one's way of looking by re-ordering natural historical, factual knowledge.

Notably, the notion of ordering figures prominently in the Philosophical Investigations too, with Wittgenstein explaining his philosophical aims in these terms: 'We want to establish an order into our knowledge of the use of language: an order for a particular purpose, not the order. For this purpose we shall again and again emphasize distinctions which our ordinary forms of language make us overlook. [...]' (PI 2009: 132) This, I believe, expresses the same basic methodological idea as the conceptual-investigation remark. There are philosophically significant features of our use of language, i.e. distinctions that we may easily overlook - just as we might overlook certain structural similarities between plants. In response to problems that arise as a consequence of this, we may then emphasize those features (like structural similarities between plants), and by so doing establish an order in our 
knowledge of language use that facilitates the perception of relevant distinctions. ${ }^{5}$ But while observing certain distinction may be important for getting clear about certain philosophical problems, other distinctions may need to be emphasized in order to get clear about other philosophical problems. What one arrangement highlights another one might eclipse. Consequently, there is no philosophically privileged order - like complete logical analyses in the Tractatus. Rather Wittgensteinian philosophical orderings of the knowledge of language use are problem relative. (Cf. PI 2009: 91; see Kuusela 2008: 81ff.) Note that just as in the remark on conceptual investigation here too Wittgenstein speaks of, not collecting or establishing facts about language use, but of ordering knowledge we already possess (i.e. knowledge of the use of language).

As regards the notions of ordering and mode of representation, Wittgenstein also writes: 'Who brings about an order to where there was no order before, introduces a new picture.' (MS 117: 264; cf. MS 120: 143v) He is speaking here of philosophical pictures characteristic of which is that they represent matters as being in a certain way. For instance, such a picture might portray first person expressions of pain as true/false propositions about inner states, or alternatively, as manifesting inner states. A picture in this capacity may then help to solve a philosophical problem, if it is a correct or a helpful one. Or it may block the way out of the problem, if it misleads. As Wittgenstein comments on the importance of finding the right mode of expression or a way to conceptualize a matter in philosophy: 'An unsuitable type of expression is a sure means of remaining in a state of confusion. It as it were bars the way out.' (PI 2009: 339) The role which philosophical pictures play in dealing with philosophical problems is remarked upon also in the following remark: 'What is it when the philosopher "sees" something? That the correct grammatical fact occurs to him, the

\footnotetext{
5 This, I maintain, is just what Wittgenstein does by comparing first person pain expression with expressive behaviour. By pointing out that 'pain' need not be understood as functioning as a name in the first person case, and that 'I am in pain' need not be understood as a true/false description which describes me being in a certain state, but could be understood as expressive or manifestative, he is emphasizing distinctions we may easily overlook.
} 
correct picture, i.e. that which organizes things in our mind, makes them easily accessible \& relieves the mind through this.' (MS 120: 143v) Relatedly Wittgenstein writes: “The philosopher says: 'Look at it like this—.' 'Are you still puzzled by it?' " (MS 118: 73v; cf. MS 134: 146/CV: 70)

The point I have been driving at is this: Arguably, there are many methods or techniques by means of which re-conceptualizations of the kind described in the quote about conceptual investigation, and illustrated by the pain-example, can be affected. Such a reconceptualization can be achieved simply by re-ordering the objects of study, so as to highlight specific connections between them, and to invite certain new comparisons between them. As noted, here the ordering of the objects itself constitutes a particular mode of representing them. But besides the technique of directly comparing different uses of language, Wittgenstein introduces a number of other methods and modes of representation that serve the purpose of philosophical clarification. Most notably, these methods and modes of representation include statements of grammatical rules (as exemplified by 'meaning is use'), simple language-games (for example, the shopping language-game in the Investigations), and what we might call 'natural historical pictures', i.e. examples that describe the behaviour of strange tribes, but also scenes of language learning, such as the case of a pupil with learning difficulties in the rule-following discussion, and the child who is taught to replace her natural expressions of pain with linguistic ones (see PI 2009: 1, 43, 144, 244). ${ }^{6}$ All these different methods and modes of representing language use constitute instruments of clarification that can be employed for the purpose of reconceptualization and bringing about a philosophically perspicuous order into our knowledge of the use of language, as in the case of pain-language. My emphasis here on the notion of mode of representation (Darstellungsweise) is intentional. For just this - the awareness of the

\footnotetext{
${ }^{6}$ For discussion of these different methods, see Kuusela forthcoming. For a detailed argument that 'meaning is use' constitutes a mode of representation and a tool of clarification, rather than a thesis about how the word 'meaning' is actually used or must be used, see Kuusela 2008: Chapter 4.
} 
involvement of a mode of representation, and their self-conscious use - is crucial for the difference between Wittgenstein and metaphysical philosophy.

Impressionistically but accurately enough for present purposes, we can say that metaphysical philosophy puts forward theses about necessities pertaining to its objects of investigation, i.e. reality or whatever there is in reality. Here reality includes language use, too, insofar as language is taken as philosophy's object of investigation, and any assertions about non-empirical necessities pertaining to language - about its essence or essential features - will count as metaphysical claims. By contrast, rather than putting forward such assertions, Wittgenstein's approach consists in the employment of various modes of representation with the purpose of clarification through comparisons. Here the point is not to make assertions about how things necessarily are or how they must be. Rather, what may look like theses or theories in Wittgenstein's writings only figure there as clarificatory devices. To be sure, Wittgenstein too, like metaphysical philosophers, makes statements that express necessity stronger than empirical necessity. This is exemplified by 'meaning is use' when this is interpreted as a grammatical statement or a grammatical rule rather than an empirical statement. By contrast with metaphysical philosophy, however, Wittgenstein takes the necessity expressed in a philosophical statement to be a constitutive feature of the philosopher's mode of representation, and from his point of view non-empirical necessities are not the object of the philosopher's assertions. Rather, instead of asserting anything about an alleged necessity in actual language use, a Wittgensteinian clarificatory statement (such as a grammatical rule) invites us to look at and examine language in the light of the necessity which the statement expresses. Moreover, we are invited to observe both the similarities and differences of actual language use from the philosopher's mode of representing it. An example can clarify this. 
When putting forward the grammatical rule 'meaning is use' Wittgenstein is proposing a mode of representing the use of the word 'meaning'. But his claim is not that the actual uses of the word 'meaning' (or any philosophically targeted subset) really conform to this rule. In this sense Wittgenstein is not making a claim or putting forward a thesis. Instead, the model is used as what Wittgenstein calls 'an object of comparison [...] so to speak a measuring rod' (PI 2009: 131). The grammatical rule, in other words, is a principle of organization employed to establish an order into our knowledge of the use of the word 'meaning', that is, an order amongst cases where language is used meaningfully, and of which we might be philosophically puzzled. (These cases are to be thought of in terms of use of words, Wittgenstein proposes, rather than, for example, intentional acts.) But this grammatical rule is not to be projected onto reality in the guise of a claim about a necessity pertaining to the actual use of the word 'meaning'. An example of such a claim would be that having a rule-governed use is a necessary condition of the meaningfulness of words. Arguably, however, the confusion of metaphysics which Wittgenstein refers to by saying that metaphysics confuses factual and conceptual questions lies precisely here. While a metaphysical philosopher makes a claim about a necessity pertaining to her object of investigation (in this case the use of the word 'meaning'), in Wittgenstein's view the necessity expressed is better understood as characteristic of the philosopher's mode of representing the object of investigation. In this sense we are to compare actual language use with the rule 'meaning is use', not to claim that 'meaning' is or must be used according to this rule. Wittgenstein's point is that looking at actual use in the light of this rule will enable us to account for many cases of linguistic meaning 'even if not for all'. (PI 2009: 43)

Notably, the last reservation in generality is possible, even if we restrict our attention to linguistic meaning and take the rule to express a necessity concerning linguistic meaning, because the rule constitutes an object of comparison with which actual use is not claimed to 
conform perfectly. As Wittgenstein says, such a rule or model is 'so to speak, a measuring rod'. It enables us to examine and describe, relate and compare different sort of cases of meaningful language use, and thus to establish an order into our knowledge of relevant cases. For example, established uses according to rules and more unusual uses, such as those Wittgenstein calls 'secondary uses' (FPP §§274-278), can now be related in that the otherwise rather mysterious secondary uses (that might easily seem to require an explanation in terms of intentional acts) are now described as parasitic on established uses. Onomatopoeic uses, in turn, can be described as iconic in contrast with rule-governed uses. Here meaning depends on the similarity between the sound and object of reference, whereas sound of the word is irrelevant in the case of rule-governed uses (MS 141: 3; cf. BB: 84-85). Thus Wittgenstein offers us way of ordering our knowledge of language use: as conforming to but also deviating from a rule.

The Investigations explains this contrast between metaphysics and Wittgenstein's approach by using simple language-games as examples of modes of representing language use. In this connection Wittgenstein describes his account of the role or status of philosophical models as constituting a response to the problem of dogmatism (a dilemma between unfairness and vacuity) which arises in connection with claims about necessities pertaining to reality ${ }^{7}$ :

Our clear and simple language-games [...] stand there as objects of comparison which, through similarities and dissimilarities, are meant to throw light on the features of our language. (PI 2009: 130)

For we can avoid unfairness or vacuity in our assertions only by presenting the model as what it is, as an object of comparison - a sort of yardstick; not as a preconception which reality must correspond. (The dogmatism into which we fall so easily in doing philosophy.) (PI 2009: 131)

\footnotetext{
${ }^{7}$ For a detailed discussion of the problem of metaphysics and dogmatism, and what Wittgenstein means by philosophising without theses, see Kuusela 2008.
} 
Comparisons therefore are right at the heart of Wittgenstein's philosophical approach, just as he says they are central to aesthetics and ethics. On this approach a philosopher makes no claims about necessities, but she employs statements of necessity as instruments of clarification. In this sense, rather than asserted to conform to a grammatical rule, actual language use is compared and examined in the light of such rules - or other modes of representation, such as simple language-games. As Wittgenstein also writes: "The investigation of language is a description and comparing of concepts, also with ad hoc constructed concepts.” (MS 133: 9v) Such ad hoc concepts are exemplified by simplified concepts used as objects of comparison in order to point out something about actual more complex concepts. Examples are the concept of meaning as use as precedingly interpreted, and the concept of language as a game according to rules which Wittgenstein explains in more or less exactly in preceding terms in his collaborative work with Waismann (VW, 3335/MS 302: 14) Another uncontroversial example is the concept of reading in the Investigations which Wittgenstein employs in his discussion of rule-following (PI 2009: 156157).

Philosophical explanations, conceived in this way, then are literally - like explanations in aesthetics - descriptions and comparisons, and Wittgenstein's comparison between philosophy, aesthetics and ethics does indeed go very far, reaching right into the heart of his approach. Rather than constituting metaphysical theses about necessities governing language, Wittgensteinian statements, such as grammatical rules, are instruments of describing, bringing order into, comparing and clarifying the uses of language. When employed to describe, and to bring into focus specific aspects of language use, grammatical rules can be used to point out similarities and differences between uses of words, and in this 
way they can contribute to creating a perspicuous order into language use with a view to solving philosophical problems (cf. PI 2009: 122).

\section{The inconclusiveness of arguments and uses of false explanations}

On the preceding basis we can say that, according to Wittgenstein, our understanding or appreciation of an object of interest depends, in both philosophy and aesthetics, on the adoption of specific ways of conceiving the object. This is exemplified by hearing or playing a musical phrase in a certain way as opposed to another one, and by construing the use of a linguistic expression in a certain way rather than another. In both philosophy and aesthetics we are also faced with the task of explaining and justifying to others such ways of conceiving objects. More specifically, in philosophy the introduction and adoption of a particular way of conceiving an object of study serves the purpose of solving philosophical problems, i.e. of rendering comprehensible the object of investigation, and releasing us from problems that arise in the context of some other ways of conceiving it. In this sense the justification of a philosophical account depends on its clarificatory capacity. But although there is therefore a rational basis for adopting one mode of conceiving an issue rather than another, Wittgenstein maintains that ultimately no conclusive arguments can be given for philosophical accounts in the outlined sense. The situation is the same in aesthetics and ethics. I quote again from Moore's lectures:

Reasons, he said, in Aesthetics, are "of the nature of further descriptions" [...] and all that Aesthetics does is "to draw your attention to a thing", to "place things side by side". He said that if, by giving "reasons" of this sort, you make another person "see what you see" but it still "doesn't appeal to him", that is "an end" of the discussion; and that what he, Wittgenstein, had "at the back of his mind" was "the idea that aesthetic discussions were like discussions in a court of law", where you try to "clear up the circumstances" of the action which is 
being tried, hoping that in the end what you say will "appeal to the judge". And he said that the same sort of "reasons" were given, not only in Ethics, but also in Philosophy. (Moore 1955: 19; my square brackets)

Does Wittgenstein's view that there are no conclusive arguments in philosophy, and that ultimately the acceptance of a philosophical account depends on what appeals to one, mean that philosophy is not the rational discipline that philosophers have considered it to be? Is the basis of our adoption of philosophical accounts in the end a matter of subjective or encultured preference (of what appeals to one)? I think not. Wittgenstein's explanation for the inconclusiveness of philosophical justifications is something quite different from what the explanation in terms of preferences suggests. Certainly there is no reason to think that Wittgenstein would regard the inconclusiveness of aesthetic, ethical and philosophical justifications as implying that in philosophy any view is as correct or good as any other (whatever that would mean). Let us examine this more closely.

Rather than in terms of subjective preferences, Wittgenstein explains the inconclusiveness of philosophical justifications with reference to what he takes to be a characteristic feature of the discipline: that, rather than concerned to discover and establish facts, philosophy articulates ways of organizing and arranging already established facts (PI 2009: 132; cf. BB: 44). A philosopher invites us to conceive the facts in some such way - and it is in this connection that questions about the justification of philosophical accounts arise. However, on the basis of Wittgenstein's account of what philosophy does, it can be readily explained why and how philosophical justifications may fall short of conclusiveness. The reason is that, especially in complex cases such as philosophy deals with, there seem to be always more than one possible way to order the facts. Similarly, it is possible to construe in more than one way the relative importance of different facts pertaining to an object of investigation so that, from the point of view of a certain way of ordering the facts, particular 
features of a case appear as more urgently in need of an explanation than others. ${ }^{8}$ Facts therefore underdetermine possible ways of ordering them, as well as underdetermining which facts should be in focus when explaining a case. This under-determination of possible orderings or conceptualizations then also leaves enough room for a philosopher to follow their already settled convictions when adopting a mode of conceiving an object, and to resist alternative descriptions or conceptualizations. Arguably, this is the sense in which, if a description "“doesn't appeal to him", that is "an end" of the discussion'.

The situation might be compared with interpreting a philosophical text: while certain readings can be relatively easily excluded as failing to account for the textual facts, to decide between some other readings may be more difficult, and sometimes it may be possible to hold on to an interpretation indefinitely, resisting any criticisms and other alternatives, because of how textual facts underdetermine possible interpretations. From this point of view, Wittgenstein's court analogy seems quite clear, too. In a court someone's action might be construed in a certain way in order to demonstrate how its various features count as evidence for criminal intent. But perhaps those details can also be put together differently so that they do not support the attribution of a criminal intent, after all. Hence, it may sometimes not be possible to demonstrate conclusively the correctness of competing ways of ordering the facts. Analogously, it seems understandable, how disagreement can sometimes persist in philosophy on the face of agreement about facts, without any irrationality on part of the disputing parties. It is not that philosophers fail to consider evidence for and against their

\footnotetext{
${ }^{8}$ Similarly, which concept should be applied to a case to describe it, or whether and how a rule or principle applies to a case, may sometimes be underdetermined in this way, as exemplified by questions such as whether abortion counts as murder, whether doing so and so counts as stealing, and so on. Here it may be similarly in dispute which features of the case are relevant for judging the case and for applying a concept to it.

${ }^{9}$ Wittgenstein need not be read as suggesting that a philosopher might not have respectable reasons for what they find appealing. For example, a philosopher might consider a certain difficulty as a fair price for making a certain point that she rightly regards as impossible to give up. The question then is whether there might be a better way to do justice to this point that can also release her from these associated difficulties.
} 
accounts. It is just that there is no conclusive evidence for the kind of accounts they put forward on the Wittgensteinian account.

It is also noteworthy how different philosophical backgrounds and commitments may influence the appeal of certain philosophical descriptions or accounts. As Wittgenstein observes, in philosophy a failure to appreciate a certain view may involve, not merely an intellectual difficulty, but a difficulty of the will.

What makes a subject difficult to understand - if it is significant, important $-[\ldots]$ is the antithesis between understanding it and what most people want to see. Because of this the very things that are most obvious can become the most difficult to understand. What has to be overcome is not a difficulty of the intellect, but of the will. (TS 213: 406-407/PO: 161)

This need not be taken to contradict the rational character of philosophy either. There may, of course, be cases where practical interests - for instance, relating to one's career spent arguing for a certain view - prevent one from seeing or admitting problems that one ought to admit. However, ultimately a certain persistence seems part of rational conversation in that holding on to a view, and trying to stretch it to cover what it has difficulty to explain seems to be just what examining and developing a philosophical account requires. By contrast, giving up on an account very easily would not allow one to properly examine its strengths and weaknesses or to develop it further on the face of difficulties. Hence, it is not the case that a philosopher's will, their wanting to see things in a certain way and hoping a particular account to turn out as correct, is necessarily in conflict with the aspiration of philosophy to be a rational discipline. That would be too simple.

Wittgenstein's emphasis on the importance of false theories in philosophy and aesthetics can be connected with this. As he explains in the very first quote, a false explanation is useful for finding the right explanation or it constitutes part of the way that 
leads to the correct one. This, I take it, is because seeing where exactly and why an account fails is crucial for correcting it. Moreover, as Wittgenstein warns, there tends to be something correct in any philosophical account: it might correctly capture some aspect or aspects of the matter, even if it fails to capture others. As he writes: 'In a certain sense one cannot take too much care in handling philosophical mistakes, they contain so much truth. [New parag.] It is never a matter of simply saying, this must be given up.' (MS 112: 99r; Z §460, except the last sentence) Thus, an account that generally speaking fails may still be able to explain something important. ${ }^{10}$ Finally, even if an account cannot explain the aspects of the case it was intended to explain, it might still point to something that requires explanation which other accounts have not paid sufficient attention. Thus a false account might have something right about it in more than one sense.

Relatedly, Wittgenstein sometimes speaks of getting rid of the misleading aspect of a philosophical account by acknowledging its origin. (MS 142: 11; MS 157b: 13v; CV: 21; for discussion, see Kuusela 2008: 120ff.) The point is that such an acknowledgement of origin for instance, that there were certain examples from which the account was derived from or based on - can help to recognize the account for what it is, i.e. a model and a mode of representation, not something to which reality, allegedly, must correspond. Consequently, it becomes possible to make less rigid and dogmatic use of the model. Rather than imposing the model onto reality and trying to make reality fit it, the model can now be used to throw light on the objects of investigation in the role of an object of comparison. In this sense Wittgenstein sometimes speaks of using philosophical models as centres of variation, whereby the function of such a centre is to help us see a class of cases in an orderly fashion as ordered around centres to which other particular cases or types are related as variants. (MS

\footnotetext{
${ }^{10}$ In this regard Wittgenstein says that, even though his early account of propositions as pictures is too simple, it does capture certain aspects of the grammar of propositions. (MS 108: 52; MS 110: 164/TS 213: 83; MS 111: 107)
} 
$115,221)$ This is a further way in which an account that strictly speaking does not correctly capture an actual case can nevertheless help to understand it.

To conclude, rather than to raise concerns about the rational character of the discipline of philosophy, Wittgenstein's view of the inconclusiveness of philosophical arguments could instead be used to explain the lack of agreement in philosophy as opposed to science. Importantly, seen from Wittgenstein's point of view, the lack of agreement in philosophy need not be understood as a defect that ought to be fixed as soon as possible in order to align philosophy with science. According to Wittgenstein's view, rather than in the business of establishing facts, philosophers are in the business of spelling out modes of representing and ordering facts. As explained, in the latter case there are ultimately no conclusive arguments. Even if it may be part of the notions of a fact that they can be agreed upon, the same need not be true of different modes of representation. Philosophy, we might say with Wittgenstein, is not a discipline where we are trying, but failing, to agree on any particular true/false descriptions of reality. Rather, it is a discipline, where we develop different modes for describing reality. Therefore it should come as no surprise that philosophers disagree. ${ }^{11}$ To freely paraphrase J. L. Austin, occupying different points of view and disagreeing might not only be an occupational hazard in philosophy. It might be the occupation itself.

\section{Bibliography}

Kuusela, Oskari (2008): The Struggle Against Dogmatism: Wittgenstein and the Concept of Philosophy. Cambridge. MA: Harvard University Press.

\footnotetext{
${ }^{11}$ Lastly, one might wonder whether the proposed interpretation of Wittgenstein's views on agreement is in conflict with his remarks according to which philosophy only states what everyone grants to it. (PI §599, cf. 126). Arguably there is no conflict, although the discussion of this issue is beyond the scope of this article. In short, rather than expecting anyone to agree on true philosophical theses, Wittgenstein only assumes agreement on the use of clarificatory devices in the sense explained earlier. Such devices, however, are: 1) much easier to agree upon than any philosophical theses. 2) Agreement is a condition for their use in that I can hardly clarify anything to you in terms you do not accept. For discussion, see Kuusela 2008: 247ff.
} 
Kuusela, Oskari (forthcoming): Logic as the Method of Philosophy: Wittgenstein's Philosophy of Logic in Relation to Frege, Russell, Carnap, and Others.

Moore, G. E. (1955): 'Wittgenstein's Lectures in 1930-33', Mind 64. No. 253, pp. 1-27.

Wittgenstein, Ludwig (1958): Preliminary Studies for the "Philosophical Investigations"

Generally Known as the Blue and Brown Books. Oxford: Basil Blackwell. (BB)

Wittgenstein, Ludwig (1967): Zettel. Anscombe ,G. E. M. and von Wright, G. H. eds. Oxford: Basil Blackwell. (Z)

Wittgenstein, Ludwig (1980): Remarks on the Philosophy of Psychology, Vol 1. Anscombe, G. E. M., von Wright, G. H. eds. Oxford: Blackwell. (RPPi)

Wittgenstein, Ludwig (1993): Philosophical Occasions 1912-1951. Klagge, J. \& Nordmann A. eds. Indianapolis: Hackett Publishing Company. (PO)

Wittgenstein, Ludwig (2000): Wittgenstein's Nachlass, The Bergen Electronic Edition. Oxford: Oxford University Press.

Wittgenstein, Ludwig (2009): Philosophical Investigations, including Philosophy of Psychology - a Fragment. Oxford: Wiley-Blackwell. (PI and PPF)

Wittgenstein, Ludwig, Waismann, Friedrich (2003): The Voices of Wittgenstein: The Vienna Circle, Ludwig Wittgenstein and Friedrich Waismann. London: Routledge. (VW) 